\section{Offspring of scientists}

SIR - R. C. Connolly ${ }^{1}$ comments that the sex ratio (proportion of the total population who are male) of 0.5278 among the offspring of artists ${ }^{2}$ may be linked to the size of the artists' families. Reviewing the data, I find an average of 2.333 children per artist in the group (of 1,489 artists), and indeed Connolly, judging from the sex ratio, predicted that the average might be between two and three. But family size considerations appear unable to account for the very low sex ratio of 0.4956 among the offspring of 1,882 scientists and mathematicians, where the average number of children is 2.742; Connolly quoted sex ratios of 0.5294 and 0.5271 for families of two and three children respectively, for the United Kingdom generally. The 0.4956 sex ratio for the scientists' and mathematicians' families differs significantly $(P>0.001)$ from even the lower of the above two values given by Connolly. There remains a possibility of a link between parentage and offspring sex ratio. Studies such as that of Crawford $e t$ $a l .^{3}$ are of considerable value in this context.

\section{R. A. Beck}

49 Curzon Avenue,

Stanmore, Middlesex HA7 2AL, UK

R. C. Connolly Replies - R. A. Beck's further analysis of his data on the offspring of $\operatorname{artists}^{1}$ is to be welcomed, not least because it accords with my suggestion of probable family size in his cohort ${ }^{2}$ but also because it contributes yet more information to our extensive but incomplete understanding of the control of the sex proportion in human populations.

His new data (see above) on sex proportions of scientists and mathematicians in 1882 must be reviewed in the light of population statistics at that time rather than directly with my figures which are secondary sex proportions (at birth) from 1956 onwards. As has been noted $^{4}$, the sex-proportion at birth is not a stable value and postnatal death rates which would be reflected in the quoted family sizes also show marked secular variation $^{5}$.

The population structure of the relevant years for England and Wales around Beck's observations derived from tables published by the Registrar General and reviewed by Britton and Edison ${ }^{5}$ and Hocking ${ }^{6}$ give birth rates with the following sex-proportions:

$$
\begin{array}{ll}
1871-75 & 0.5096 \\
1876-80 & 0.5093 \\
1881-85 & 0.5093 \\
1886-90 & 0.5088
\end{array}
$$

Values for living children in the population in 1881 at different ages are NATURE · VOL 358 - 20AUGUST 1992

as follows:

$$
\begin{array}{cc}
0-4 \mathrm{yr} & 0.4992 \\
5-9 \mathrm{yr} & 0.4985 \\
10-14 \mathrm{yr} & 0.5007 \\
15-19 \mathrm{yr} & 0.4980
\end{array}
$$

I am not aware of published data for these periods relating sex-proportions to birth order which would complete the figure and allow a valid comparison for Beck's data on scientists and mathematicians but the sex-proportions quoted above for whole families do approach Beck's cohort value of 0.4954 without knowing family size.

It is very likely that there is a link between parental genetics and sexproportions but the extent of this contribution is still inadequately understood and sadly, for populations in the last century, the census figures may be less accurate and thus less representative of the population as a whole than the results of more recent surveys.

\section{R. C. Connolly}

Department of Human Anatomy and Cell Biology,

PO Box 147 .

University of Liverpool, Liverpool L69 3BX

1. Beck, R. A. Nature 356, 189 (1992)

2. Connolly, R. C. Nature 357, 272 (1992)

3. Crawford, E., Gilmore, D. \& James, W. H. Nature 357 272 (1992).

4. Shaw, C. Popul. Trends 57 26-29 (1989)

5. Britton, M., Edison, N., Popul. Trends 46, 22-25 (1989).

6. Hocking, W. S., J. Inst. Actuaries 74, 340-344 (1948). $\square$ This correspondence is now closed. Editor, Nature.

\section{NIH patent rights}

SIR - The pending patent application filed by the National Institutes of Health (NIH) on 2,421 brain cDNA clones obtained by J. Craig Venter and colleagues (so-called Expressed Sequence Tags) constitutes a body of intellectual property owned by the US government. While the wisdom of the NIH filing of this patent, now a continuation-in-part application, is a matter of legitimate controversy, the deed is done. If some or all of the patent claims covering uses of the cDNA clones (for example, for the identification of human brain tissue, the creation of probes, antisense oligonucleotides and vectors, and mapping the expressed sequences on chromosomes) are eventually allowed by the US Patent and Trademark Office, which is by no means certain, the NIH will be entitled to receive licence fees and product royalties from companies that make use of the claimed subject matter.

Venter's new undertaking is described as a "nonprofit research centre" but its investors are also planning a new biotech company to develop and market products from this technology (see Nature 358, 95; 1992). We trust that any patent rights will not be given freely to a single company for the commercial benefit of a few investors.

If patents are issued, it is to be hoped that the NIH will negotiate appropriate licence fees and royalties from all commercial users, so that this taxpayerfunded research will generate capital to further the endeavours of one of the world's greatest nonprofit research centres, the NIH.

\section{Thoru Pederson}

Worcester Foundation

for Experimental Biology,

Shrewsbury, Massachusetts 01545, USA

\section{Leeds inquiry}

SIR - In his response (Nature 358, 102; 1992) to your leading article about allegations against me of scientific misconduct, J. J. Walsh, the Registrar of the University of Leeds, claims that his inquiry "followed guidelines modelled on those recommended by the Royal College of Physicians". These call for thorough investigation of all related matters and for protection of the complainant. I had emphasized that I was more concerned in the subsequent events and in particular with attacks on my post which I believed were related to my discovery of the fraud. It is most regrettable that the university constructed a remit for inquiry which seemed to have excluded the very matters with which I was most concerned.

I have no doubt a truly independent investigation of the evidence I presented would arrive at substantially different conclusions from those of the Leeds panel. If Walsh is convinced that the investigation by the University of Leeds did not avoid the main issues, and that senior university staff had no significant role in the steps leading to my dismissal, then he should welcome confirmation of their findings by truly independent investigators. I hope he will accept this challenge.

For the record, Walsh refused all my requests for investigation until Nature indicated an interest in my case. When the "three wise men" inquiry was announced, the vast majority of people thought a "cover-up" to be the most likely consequence. Rightly or wrongly, this view of self-policing by universities appears to be universal. I am offering the University of Leeds an opportunity to demonstrate that this cynicism is unjustified.

\section{Chris Chapman}

21 Newlaithes Road,

Horsforth,

Leeds LS18 4LG, UK 